\title{
INSTALLATION OF OBTAINING WELDING WIRE BY FRICTION EXTRUSION METHOD
}

\author{
Desislava Krusteva*, Yasen Hadjitodorov \\ and Plamen Tashev \\ Institute of Metal Science, Equipment and Technologies \\ with Hydro- and Aerodynamics Centre "Acad. A. Balevski", \\ Bulgarian Academy of Sciences, \\ 67, Shipchenski Prohod Blvd, 1574 Sofia, Bulgaria, \\ e-mails:desislava.v.krusteva@gmail.com; jason@ims.bas.bg; \\ e-mail:ptashev@ims.bas.bg
}

\begin{abstract}
Equipment of obtaining welding wire by means of the friction extrusion method has been developed. This method allows the production of specialized wires for tungsten inert gas welding by addition of relevant modifiers, as micro-and nanoparticles in the main material. The schemes of fixing of the devices and tools used in the extrusion process are presented, as well the characteristics of the equipment.

Keywords: friction extrusion method, aluminum chips, nanomaterials, equipment for extrusion by friction, measuring equipment.
\end{abstract}

\section{INTRODUCTION}

Researches and experiments conducted over the past 20 years show that the extrusion by friction of aluminum wires can utilize the waste materials (chips) from mechanical processing and allow the use of additives as modifiers in the material. This makes it particularly suitable for the production of specialized wires for tungsten inert gas welding. Although not well developed to this date, this method is gaining popularity.

During 1993 this method is invented and patented by W. M. Thomas et al. at the Welding Institute, Cambridge, UK. A few years later, in 1999 Gronostajski et al. investigated aluminum chips recycling and found that direct recycling can save about $40 \%$ of material, $26-31 \%$ of energy consumption, and $16-60 \%$ of labor costs. [1]

${ }^{*}$ Corresponding author.

DOI: 10.7546/EngSci.LVII.20.02.05 


\section{STATEMENT OF THE PROBLEM}

A universal lathe is modified for conduction of the experiments as shown in Fig. 1(a). Special holders for fixing of the friction tools to the machine are designed, providing the required accuracy and the proper alignment between the two friction parts, Fig. 1(a, b, c).

The holders are made of steel C45. Th heat-resistant steel 4X5MFS is used for manufacturing of the friction tools. The primary application of this steel is for hot stamping tools, intended to work continuously at high temperatures. The heat treatment of heat-resistant steel 4X5MFS is given in Table 1 and the mechanical properties at temperature $20^{\circ} \mathrm{C}$ in Table 2 .

The experimental installation is shown in Fig. 2. The material container 3 is fixed by the holder 2 , which is mounted on the machine spindle 1 . The punch 5 which is the stationary part of the friction couple and exerts the pressure required for the extrusion is fixed by the holder 6 . It is mounted to the tailstock of the machine 7 by flange with a Morse taper 8 and is centered

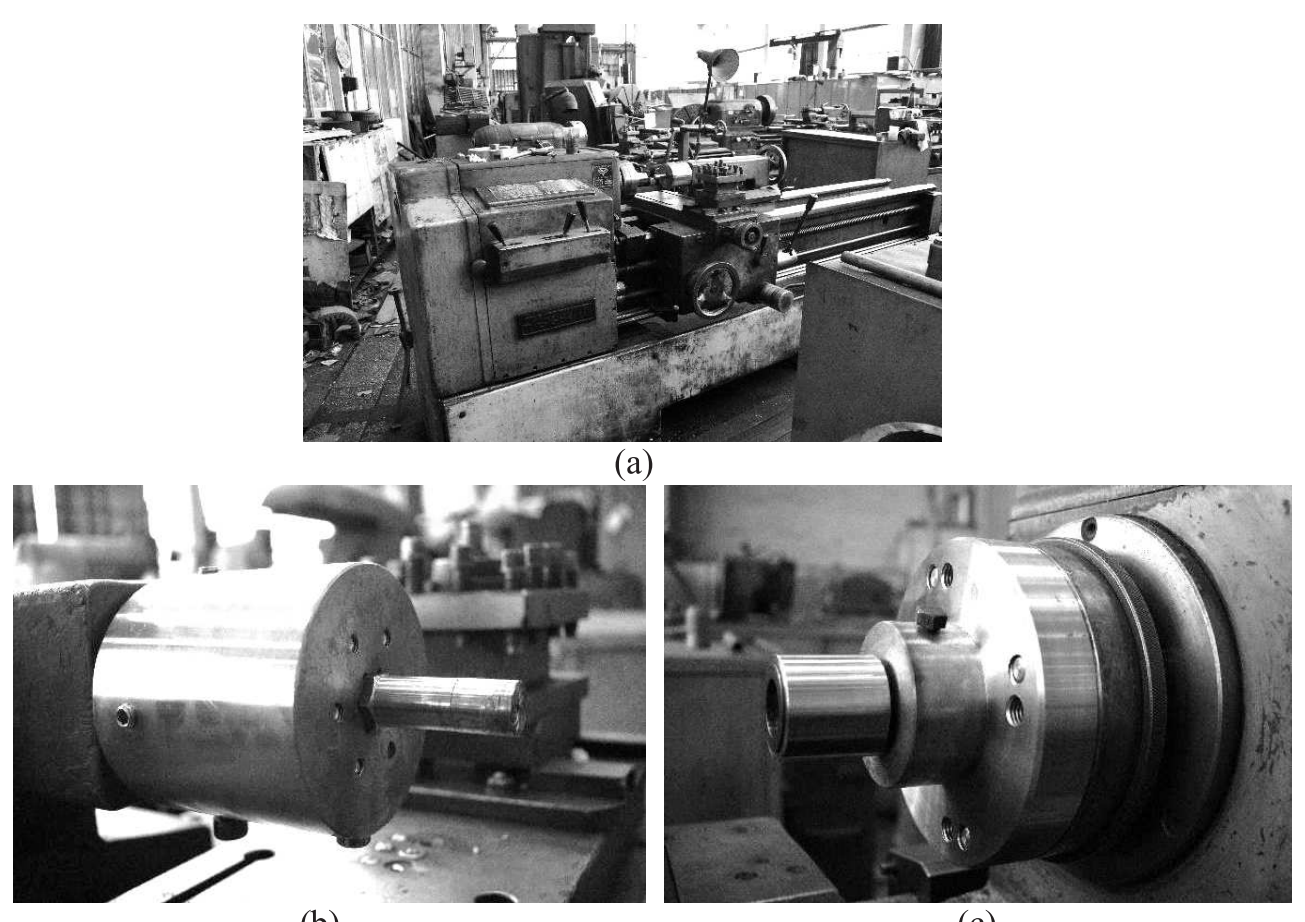

(b)

(c)

Fig. 1. Modified universal lathe: (a) setup for friction extrusion of welding wire; (b) punch holder; (c) container holder 
Table 1. Heat treatment of heat-resistant steel 4X5MFS

\begin{tabular}{|c|c|c|}
\hline Temperature, ${ }^{\circ} \mathrm{C}$ & Time, $\mathrm{h}$ & $\mathrm{HRC}_{\partial}$ \\
\hline 590 & 2 & 47 \\
\hline
\end{tabular}

Table 2. Mechanical properties of heat-resistant steel 4X5MFS

\begin{tabular}{|c|c|c|c|c|}
\hline Size, $\mathrm{mm}$ & $\sigma_{b}, \mathrm{MPa}$ & $\sigma_{T}, \mathrm{MPa}$ & $\mathrm{KCU}, \mathrm{kJ} / \mathrm{m}^{2}$ & Heat treatment \\
\hline 10 & 1750 & 1480 & 570 & $\begin{array}{c}\text { quenching } 1000-1020^{\circ} \mathrm{C} \\
\text { annealing } 530-560^{\circ} \mathrm{C}\end{array}$ \\
\hline
\end{tabular}

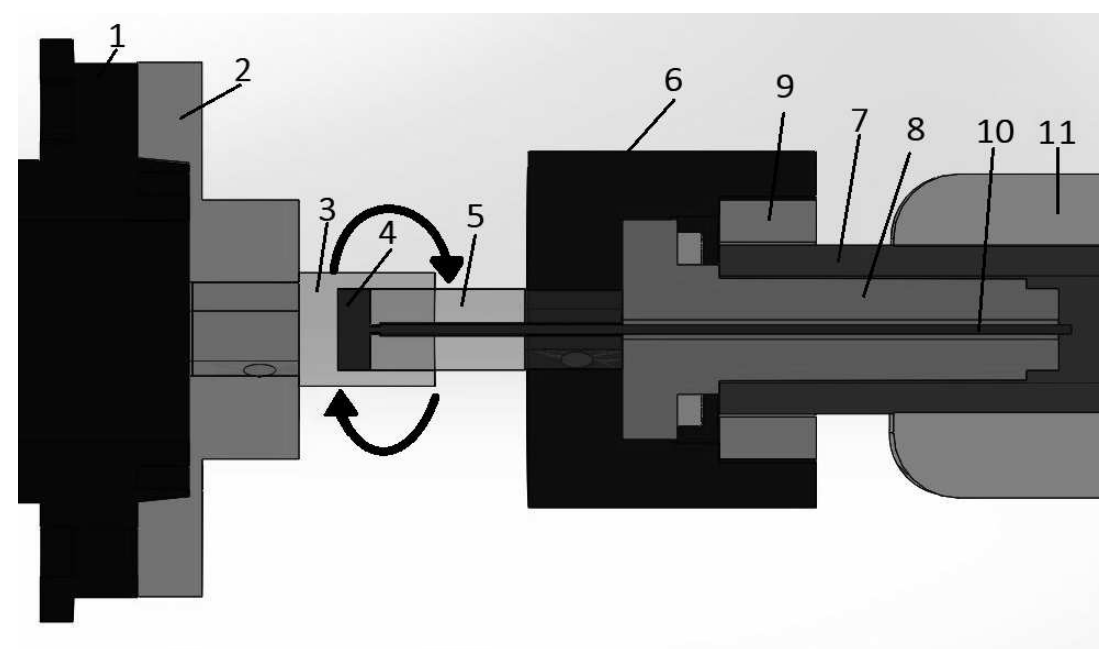

Fig. 2. Experimental setup for friction extrusion

and secured against turning through a ring 9. The material container 3 is filled with aluminum alloy chips 4 with dimensions from $1 \mathrm{~mm}$ to $3 \mathrm{~mm}$. Chips are prepressed on a hand screw press at a temperature of $20^{\circ} \mathrm{C}$ with a maximum force of $50 \mathrm{kN}$.

The container 3 is placed on the machine and the spindle is rotated at speeds in the range from 125 to $300 \mathrm{rpm}$. The pressure of $76 \mathrm{kN}$ is applied by means of punch 5 and held so in order to increase the temperature due to the friction between the surface of the pressed chips and the tool face. The time required to reach a temperature of $475^{\circ} \mathrm{C}$ is from 10 to 45 seconds depending on the speed and shape of the tool, after which the applied pressure is increased to $103 \mathrm{kN}$. The welding wire 10 in Fig. 2 is extruded through an integrated calibration hole with the required diameter at the face of the punch 5 . Then the wire passes through the hole with larger diameter in the tail of the tool 


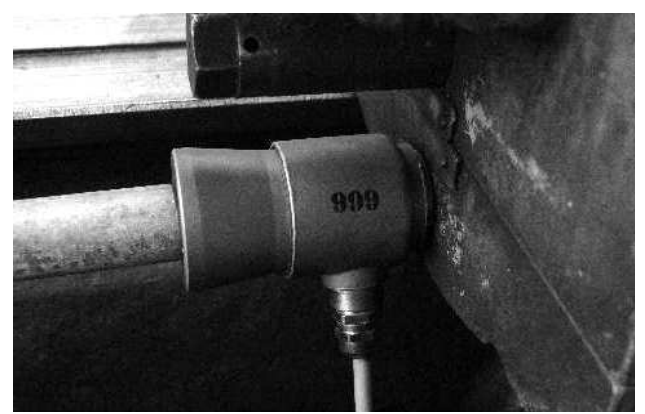

Fig. 3. Tensometric force meter

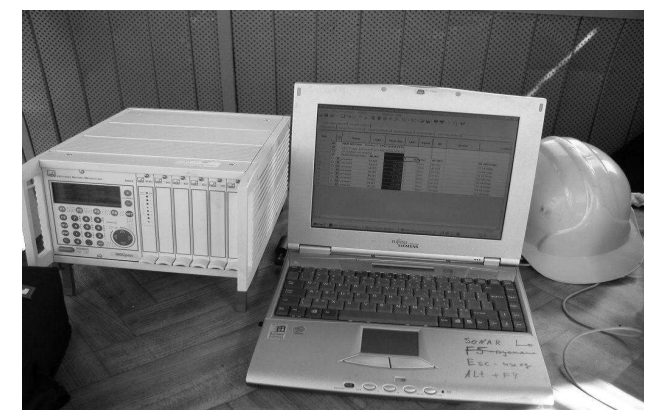

Fig. 4. Measuring station (mobile)

Table 3. Characteristics of pyrometer IL-92

\begin{tabular}{|l|c|c|}
\hline Parameter & IR & Type K thermocouple \\
\hline Measuring range & $-50 \div+2200{ }^{\circ} \mathrm{C}$ & $-50 \div+1370{ }^{\circ} \mathrm{C}$ \\
\hline Accuracy & $\pm 1 \% \div \pm 2 \%$ & $\pm 1.5 \%$ \\
\hline Resolution & $0.1{ }^{\circ} \mathrm{C} ; 1^{\circ} \mathrm{C}$ & $0.1{ }^{\circ} \mathrm{C} ; 1^{\circ} \mathrm{C}$ \\
\hline Reaction time & $150 \mathrm{~ms}$ & - \\
\hline Spectral range & $8 \div 14 \mathrm{um}$ & - \\
\hline Work temperature & $0 \div 50{ }^{\circ} \mathrm{C}$ & $0 \div 50{ }^{\circ} \mathrm{C}$ \\
\hline
\end{tabular}

and continues through Morse tapper 8 and tailstock barrel 7, while gradually cools. The extrusion time is about $27 \mathrm{sec}$ and the welding wire obtained is 50 $\mathrm{cm}$ long, defined by the volume of the container 3 .

During the extrusion process a Tensometric force meter is used for measuring the applied force, Fig. 3. It is fixed on the lower part of the tailstock. The force measurement is carried out in real time by digital registration equipment MGCplus Hottinger Baldwin Messtechnik. All procedures for calibration, resetting and measuring the force in required moments are performed by using the computer and the specialized CATMAN software for work with the Tensometric force meter (Fig. 4). The collected information from extrusion process is stored on computer HDD and is used for analyses [2].

For temperature control an IL-92 pyrometer, shown in Fig. 5, with the following characteristics is used, as given in Table 3.

The pyrometer is placed on a tripod at a distance of $1.2 \mathrm{~m}$ from the test objects, focusing the infrared radiation as precisely as possible at this distance and the plane of the infrared measurement is perpendicular to the normal of the surface of the test object. IL-92 is pyrometer, which can freely measure the temperatures, varying within a wide range, including liquid metal [3]. 


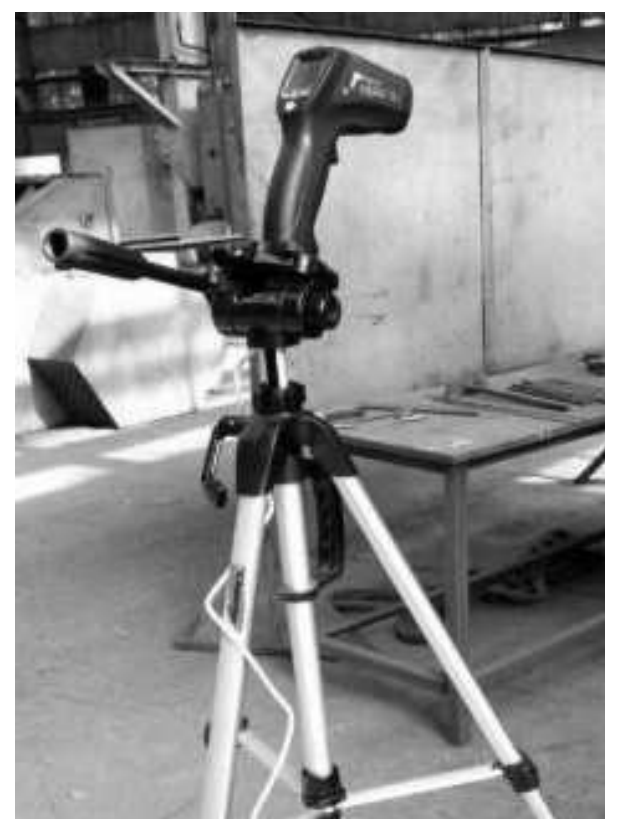

Fig. 5. IL-92 pyrometer

The measurement is performed by starting the pyrometer in continuous measurement mode and connecting it to a computer with a program developed by MATLAB. One pyrometer report allows the measurement of 6 temperatures (current, maximum, average, minimum, internal and the temperature read by a thermocouple, each recorded with accuracy of $0.1^{\circ} \mathrm{C}[4]$.

\section{CONCLUSION}

- Universal lathe is modified to meet the requirements for welding wire extrusion through friction experiments.

- The equipment and tools needed for performing the experiments for friction extrusion are designed and manufactured.

- Fixing holders, providing required accuracy and proper alignment between the two friction parts, are designed and manufactured.

- A number of experiments have been conducted with different values of the basic parameters of the process, as well as different shapes of friction parts of the tool that allow determining the optimal values of the process.

- The obtained results do not fully meet the objectives of the experiment, and therefore the work is continuing to improve the technology. 


\section{REFERENCES}

[1] H. Zhang, X. Li, X. Deng, A. P. Reynolds, and M. A. Sutton, Numerical Simulation of Friction Extrusion Process, Journal of Materials Processing Technology (2018) 253 17-26, ISSN: 0924-0136

[2] R. Merdjanov, I. Atanasov, B. Abadjiev, and S. Todorov, System for monitoring the forces in the tension bundles of reinforced concrete shell, Engineering Sciences (2009) XLVI (2) 66.

[3] Manual for use of IL pyrometer series by Interlabor EOOD.

[4] Algorithm for automatic calibration of pyrometers type IL.

Received November 15, 2019

Engineering Sciences, LVII, 2020, No. 2 